\title{
PASAR HETEROTOPIA: TIPOLOGI BARU SEBUAH PASAR
}

\author{
Jasson $^{1)}$, Doddy Yuono ${ }^{2)}$ \\ 1)Program Studi S1 Arsitektur, Fakultas Teknik, Universitas Tarumanagara, peculiargre23@gmail.com \\ 2) Program Studi S1 Arsitektur, Fakultas Teknik, Universitas Tarumanagara, masdoddyyuono@gmail.com
}

\begin{abstract}
Abstrak
Pasar, selain mejadi tempat terjadinya transaksi ekonomi, juga memiliki peran penting sebagai jaringan sosial sekaligus media unjuk eksistensi diri oleh berbagai pihak. Terutama kepada generasi milenial yang sekarang cenderung menikmati kegiatan transaksi secara virtual. Tingginya laju digitalisasi kegiatan ekonomi saat ini, beserta perluasan jaringannya kepada media sosial, telah meredefinisikan kegiatan belanja sebagai salah satu (komoditas) pengalaman unik yang wajib dialami dan dibagikan para milenial untuk memperkuat kualitas sosial dirinya. Generasi milenial memandang kegiatan transaksi-ekonomi sebagai salah satu cara untuk memperoleh pengalaman baru yang patut dibagikan. Di sisi lain, bercermin kepada tendensi sama di aspek-aspek lain, fenomena digitalisasi ini turut memperkuat kecenderungan individualistis milenial, mengisolasi diri mereka dari kontak langsung di dunia nyata. Perubahan sistem ekonomi ke arah digital ini juga menjadi ancaman baru bagi keberlanjutan praktik-praktik ekonomi konvensional yang ada, terutama sistem pasar tradisional dengan tingkat interaksi dan partisipasi sosial sangat tinggi antar pengunanya. Melalui proyek ini, peneliti berusaha menawarkan bentuk tipologi baru pasar tradisonal yang mendukung kedekatan sosial antar penggunanya terjalin intens, serta mempertahankan esensi pasar tradisional sebagai pusat sosial masyarakat. Rancang tipologi arsitektur yang ditawarkan oleh peneliti juga diharapkan memberi peluang seluas-luasnya bagi para penggunanya, teristimewa generasi milenial, untuk mengekplorasi berbagai peran sosial mereka dalam kegiatan ekonomi saat ini.
\end{abstract}

Kata kunci: heterotopia; interaksi sosial; milenial; pasar; tipologi

\begin{abstract}
The market, aside from being the place where economic transactions occur, also has an important role as a social network as well as a medium to showcase the existence of self by various parties. Especially to the millennial generation who now tend to enjoy transaction activities virtually. The high rate of digitalization of current economic activities, along with its network expansion to social media, has redefined shopping activities as one of the (commodity) unique experiences that must be experienced and shared by millennials to strengthen their social quality. Millennials view economic-transaction activities as a way of gaining new experiences that deserve to be shared. On the other hand, reflecting on the same tendency in other aspects, the phenomenon of digitalization has helped strengthen millennial individualistic tendencies, isolating themselves from direct contact in the real world. The change in the economic system to digital direction is also possesing new threat to the sustainability of existing conventional economic practices, especially traditional market systems with a very high level of interaction and social participation among its users. Through this project, researchers are trying to offer a new typological form of traditional markets that support the social closeness between their users, intensified, and maintain the essence of traditional markets as a social center of society. The design of the architectural typology offered by researchers is also expected to provide the widest possible opportunity for its users, especially the millennial generation, to explore their various social roles in current economic activities.
\end{abstract}

Keywords: heterotopi; marketplace; milennials; social interaction; typology 


\section{PENDAHULUAN}

\section{Pasar Tradisional Dalam Era Kekinian}

Pasar telah menjadi bagian tak terpisahkan dalam perjalanan peradaban manusia. Lahir dari dorongan bertransaksi dari masyarakat untuk memenuhi kebutuhan hidup, pasar menjelma sebagai institusi urban yang mewadahi praktik ekonomi dalam tubuh masyarakat guna melayani kebutuhan kolektif mereka. Dalam praktik sehari-harinya, pasar juga menjadi ruang pembentukan berbagai relasi kuasa, baik antara pedagang-pembeli (transaksi), antar sesama pedagang (paguyuban), maupun seluruh penggunanya dengan ruang pasar itu terjadi.

Catatan tertua tentang tradisi pasar di Indonesia ditemukan pada prasasti Truyan dan Muncan mengenai pasar tradisional sepanjang sungai Berantas dan Bengawan Solo di Jawa. Signifikansi pasar semakin terasa tatkala kemunculan sistem rotasi pasar harian di kerajaan mataram kuno pada abad ke-11. Selain sebagai upaya pemerataan distribusi komoditas, sistem penempatan pasar-pasar harian ini juga mengindikasikan dengan jelas kuasa pasar di tengah kehidupan masyarakat. Interelasi ini berjalan terus hingga masa kini, dimana kontribusi sosioekonomi pasar-pasar tradisional masih berjalan kuat. Per tahun 2010, sebagai studi kasus, pemkot kota Solo berhasil meraup keuntungan sebesar 12,5 miliar rupiah dari retribusi pasar tradisional dan PKL sepanjang kota Solo. Selain sebagai sarana transaksi, pasar juga menjadi wadah pertukaran dan pembentukan berbagai ide dan karya lainnya. Seperti yang ditemukan pada Pasar Senen dimana seniman-seniman ternama Indonesia seperti Affandi dan Sudjojono sering berkunjung untuk mendapatkan inspirasi baru.

Melihat potensi-potensi ini, pemerintah menggalakan program-program revitalisasi pasar tradisional di berbagai daerah sejak tahun 2015. Hingga tahun 2018, Kementerian Perdagangan (Kemendag) mengklaim telah merevitalisasi 4.211 unit pasar di Indonesia. Tak hanya sebatas perbaikan infrastruktur belaka, pemerintah juga memasukan program-program baru ke dalam pasar, di antaranya pengadaan bioskop rakyat dalam pasar maupun digitalisasi sistem transaksi pada beberapa pasar. Upaya ini diharapkan bisa meningkatkan antusiasme masyarakat untuk datang dan berbelanja di pasar, terutama kaum milenial, dengan sarana teknologi penunjang yang memadai.

\section{Milenial dan Geliat Perekonomian Kiwari}

Dekade 2010-2030 menjadi periode perubahan paling dinamis dalam sejarah peradaban umat manusia. Beragam aktivitas politik, sosial, dan ekonomi global dengan cepat merengkuh kecanggihan teknologi informatika yang telah dikembangkan sejak 1990-an, dan diprediksi mencapai konvergensi total pada tahun 2042 mendatang. Situasi demikian tak mungkin terjadi tanpa partisipasi aktif dari aktor utama perubahan ini: generasi milenial.

Generasi milenial dikenal memiliki kecakapan serta ketergantungan tinggi terhadap perangkat teknologi digital. Pada survei tahun 2015 yang dilakukan lembaga Connected Life, milenial Asia-Pasifik menghabiskan waktu di depan layar gawai sebanyak rata-rata 2,8 jam setiap harinya dengan akumulasi rata-rata waktu 22,4 jam dalam satu minggu. Sebagian besar $(46 \%)$ interaksi digital yang dilakukan milenial dihabiskan di sosial media, dilanjutkan dengan menonton kanal video di YouTube (42\%) dan berbelanja daring (12\%). Praktik belanja daring ini memiliki frekuensi tertinggi ( 5 hari/minggu) dibandingkan dengan model belanja lainnya.

Di saat bersamaan, tren belanja ini ikut mempopulerkan model bisnis daring (e-commerce) sebagai peluang usaha paling potensial saat ini. Tercatat pertumbuhan sektor e-commerce di Indonesia naik sebesar 53,23 persen setiap tahunnya, dengan nilai transaksi rata-rata mencapai AS\$3,56 miliar selama periode 2011-2015. Pertumbuhan besar ini didukung pula oleh sejumlah strategi efektif: acara tahunan hari belanja online nasional (harbolnas) setiap tanggal 12 Desember dengan ragam promo yang ditawarkannya, branding intensif di media sosial demi menjaring lebih banyak konsumen setia, hingga berkolaborasi dengan beberapa perusahaan jasa logistik dan pembayaran elektronik untuk perluasan area pemasaran baru. 
Tak dapat dipungkiri bila strategi-strategi demikian berhasil menyerap hingga 5,9 juta konsumen baru pada tahun 2015.

Di balik semua potensi besarnya, budaya belanja daring dan bisnis e-commerce juga melahirkan beberapa tantangan baru. Secara aspek sosial, orientasi daring dalam aktivitas harian para milenial telah menciptakan jarak lebar dalam proses interaksi langsung terhadap lingkungan sekitar mereka. Pada praktik belanja daring sendiri tanpa sadar ikut menumbuhkan perilaku konsumtif konsumen, dengan dampak lanjutan mereduksi pertimbangan ekonomis mereka ketika berbelanja. Para milenial juga menjadi lebih rentan terhadap berbagai malpraktik transaksi, baik sebagai produsen maupun konsumen. Dalam katalog laporan pengaduan tahun 2015, YLKI menerima sebanyak 77 delik aduan terkait malpraktik belanja daring. Peringkat pertama kasus mengenai kendala penarikan kembali transaksi (20\%), disusul oleh misinformasi produk (16\%) dan masalah akses logistik (15\%).

Dalam segi ekonomi, praktik e-commerce turut mengancam keberlangsungan modelmodel bisnis dan ekonomi konvensional yang ada. Pada awal 2019 ini, ritel toko sepatu Payless menutup seluruh 2300 gerai tersisanya di Amerika Utara akibat mengalami kebangkrutan sebesar AS\$400 juta sejak 2017 lalu, menyusul tutupnya jaringan ritel Toys " $R$ " Us dan Charlotte Russe. Ketiganya sama-sama dinilai gagal menarik konsumen baru yang banyak beralih ke aplikasi Amazon. Selain daya saing yang terlampau jauh, terdapat juga potensi disrupsi e-commerce terhadap mekanisme sistem ekonomi konvensional, seperti pada kasus penjualan gula rafinasi untuk pasar industri di laman Tokopedia. Berangkat dari fakta-fakta ini, peneliti terdorong untuk melakukan riset terkait perilaku generasi milenial berorientasi daring di masa ini dan pengaruh yang ditimbulkannya terhadap keberlangsungan sistem sosioekonomi konvensional yang ada, teristimewa sistem ekonomi pasar tradisional.

\section{KAJIAN LITERATUR}

Berdasarkan Kamus Besar Bahasa Indonesia (KBBI), pasar diartikan sebagai tempat orang berjual beli. Dalam konteks abstrak, pasar juga diartikan sebagai sebuah kekuatan penawaran dan permintaan yang mengambil rupa lokasi fisik maupun aktivitas antar pelaku didalamnya.

Secara asal-usul etimologis, kata pasar diserap dari bahasa turki pazar, turunan bahasa persia bazaar dengan makna yang sama. Pemaknaan sejenis juga ditemukan pada kata market dalam bahasa inggris, yang diserap dari kosakata latin mercatus. Di saat bersamaan, pemaknaan kata-kata ini juga mendefinisikan dua tipe pasar berbeda berdasarkan tujuan kegiatan pasar itu sendiri. Bila market bersifat komersial (meraup untung sebanyak mungkin lewat kegiatan berjual beli), tujuan bazaar dilaksanakan lebih bersifat amal, yakni untuk menjaga kesejahteraan sosio-ekonomi masyarakat kota/desa yang mewadahinya. Perbedaan makna kata ini sekaligus juga membedakan tradisi pasar yang terjadi di peradaban barat maupun timur.

Terlepas dari perbedaan maknanya, sebuah pasar, menurut Lewis Mumford, terjadi untuk mewadahi berlangsungnya tiga aktivitas utama: membeli, menyimpan, dan distribusi komoditas. Ketiga kegiatan ini sekaligus juga menjadi komoditas utama yang ditawarkan dari kehadiran pasar itu sendiri: perdagangan, riba, dan jasa. Rangkaian aktvitas ini sekaligus mengukuhkan pasar sebagai salah satu institusi urban yang lahir dari dorongan kolektif masyarakatnya untuk mencapai keamanan dan ketahanan hidup harian. Terkait dengan kegiatan membeli/riba dalam pasar, Mumford, sejalan dengan pemikiran Aristoteles, mendefinisikannya sebagai usaha kompromi antar pelaku pasar untuk mencapai kesepakatan balas jasa atas transaksi komoditas yang diinginkan (bagi pembeli memperoleh produk; bagi penjual mendapatkan bayaran produksi terkait) lewat harga sejumlah uang guna menjamin ketahanan sistem di dalamnya.

Motif ekonomi pasar tradisional rupanya tidak begitu mutlak dalam sistem ekonomi pasar daring. Membaca dari tingginya intensitas belanja konsumen yang ada, terutama dari generasi milenial, telah mendorong organisasi HILL ASEAN melakukan survei terbuka pada tahun 2015 
tentang preferensi gaya hidup milenial beserta faktor-faktor pendukungnya. Lewat survei ini, ditemukan tiga faktor utama:

a. Efisiensi waktu: tendensi multitasking dalam etos kerja generasi milenial menuntut cara-cara paling efisien untuk menyelesaikan beragam tugas secara bersamaan, dan model belanja ini mampu menjawab dorongan kegiatan berbelanja mereka dalam waktu terbatas.

b. Pengalaman baru: belanja daring menawarkan pengalaman berbelanja baru bagi para milenial, sebagai pemenuhan hasrat aktualisasi diri terus-menerus akibat interaksi intens dengan teknologi real-time interface dalam gawai mereka.

c. Konektivitas sosial: masih terkait oleh hasrat aktualisasi diri secara intens, ditambah hadirnya aplikasi media sosial untuk kemudahan proses komunikasi, mendorong para milenial melakukan berbagai cara agar tetap terhubung secara sosial. Dan berbelanja daring menjadi salah satu ungkapan mereka agar tetap terhubung dengan tren-tren sosial yang terjadi.

Pada penelitian ini, penulis ingin mencari tahu seberapa besar ketiga faktor ini menjadi pendorong bagi milenial untuk melakukan kegiatan transaksi ekonomi, dan faktor mana sajakah yang penting dimiliki oleh pasar-pasar tradisional yang ada supaya bisa tetap bertahan di masa ini.

\section{METODE}

Metode pengambilan data yang digunakan oleh penulis adalah metode fenomenologis dengan teknik sampling photovoice. Metode ini digunakan mengingat kehadiran pasar sebagai sebuah fenomena ekonomi sehari-hari yang terjadi di masyarakat. Sementara teknik sampling photovoice sendiri sudah dipakai dalam penelitan-penelitian sosiologis dan antropologis. Dan kembali kepada hakikat pasar sebagai produk kebudayaan manusia, maka teknik ini dirasakan cocok untuk membantu pengolahan data yang diperlukan.

Subjek sampling yang digunakan adalah postingan instagram dengan tanda lokasi pada 22 pasar tradisional di berbagai negara. Fokus data berada pada analisis kesamaan citra-citra foto yang diambil para subjek, yakni para milenial pengguna instagram, ketika mereka bertandang ke lokasi pasar-pasar tersebut. 


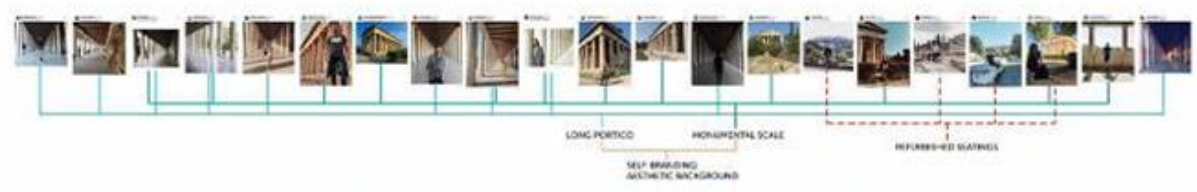

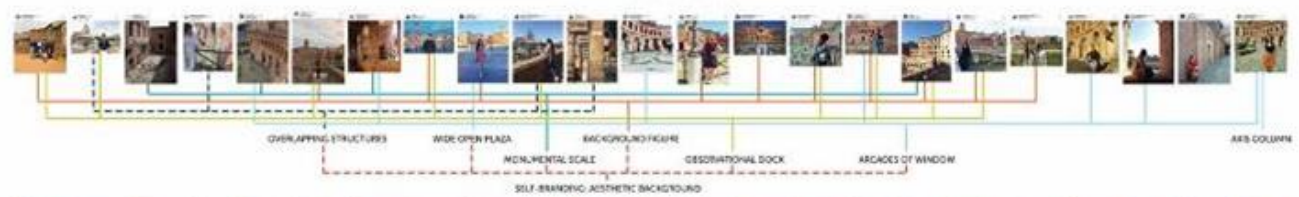

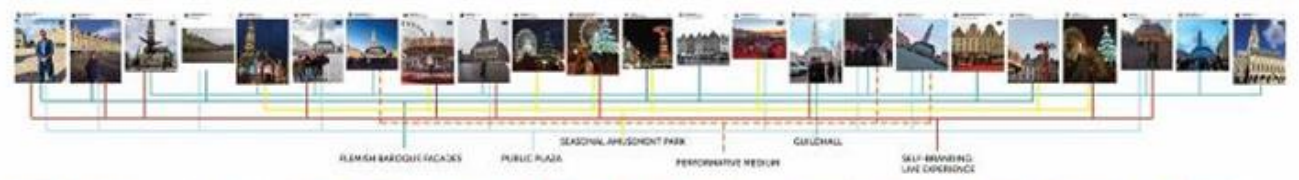

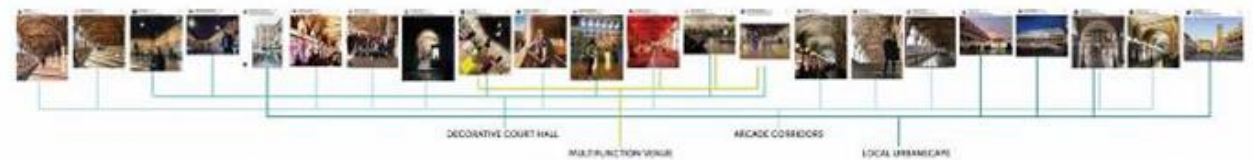
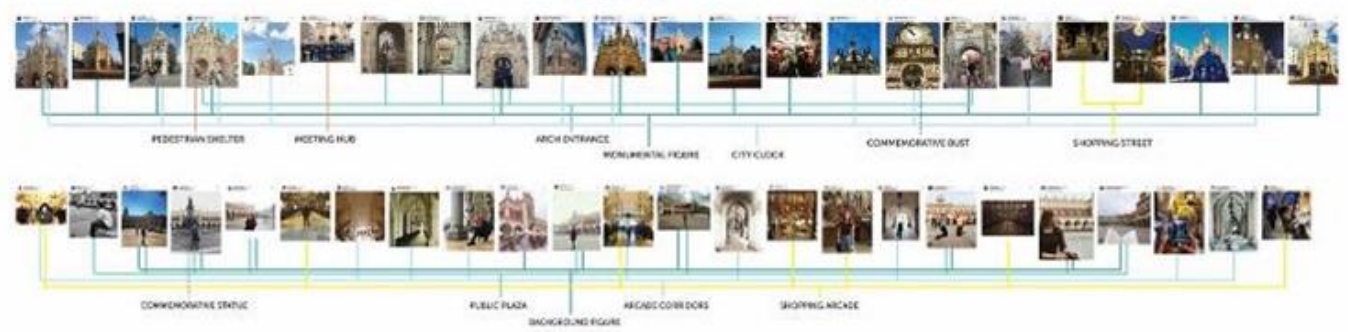

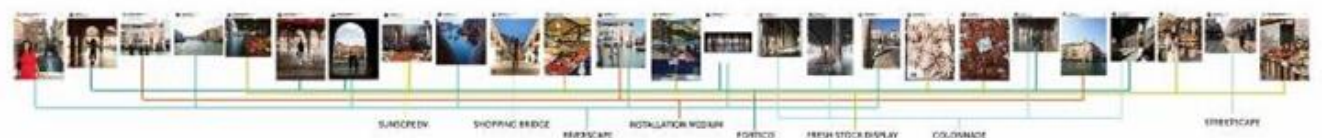
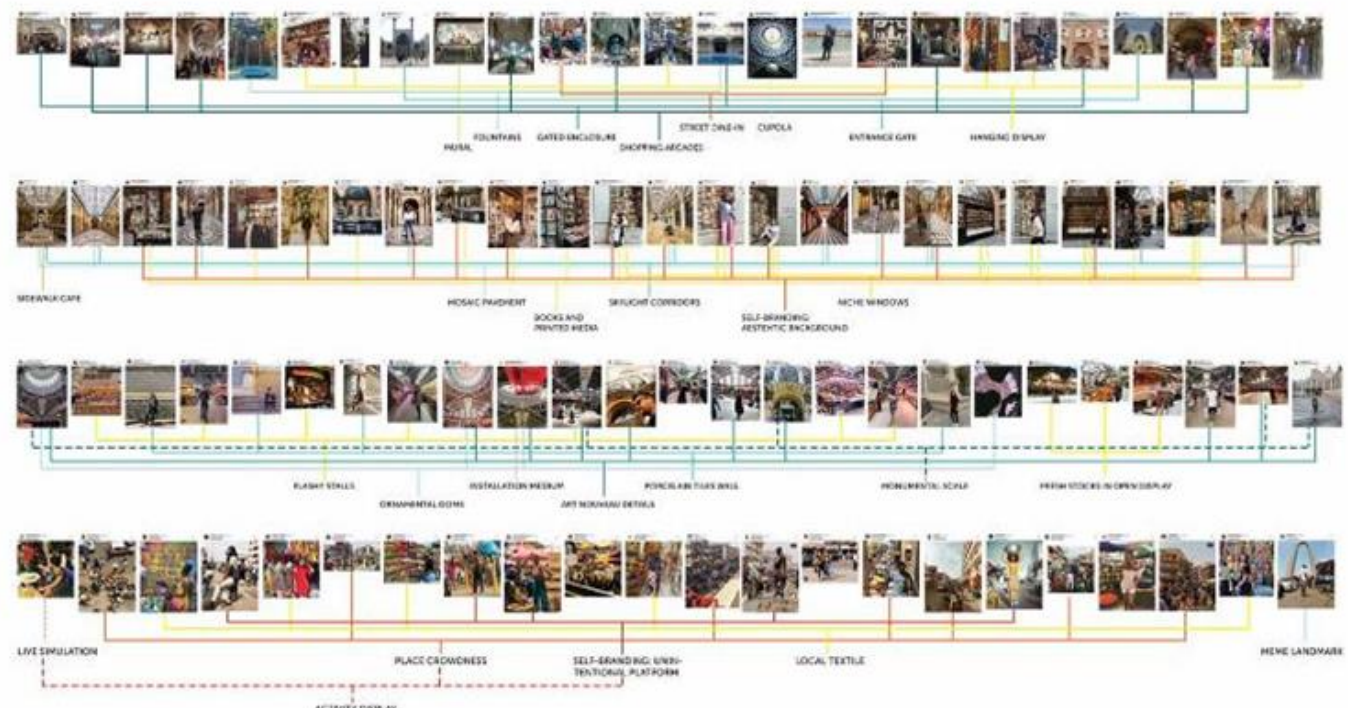

Gambar 1. Kumpulan citra pasar pada laman pencarian Instagram berbasis koordinat lokasi yang berhasil dikumpulkan oleh penulis.

Sumber: Instagram, 2019 

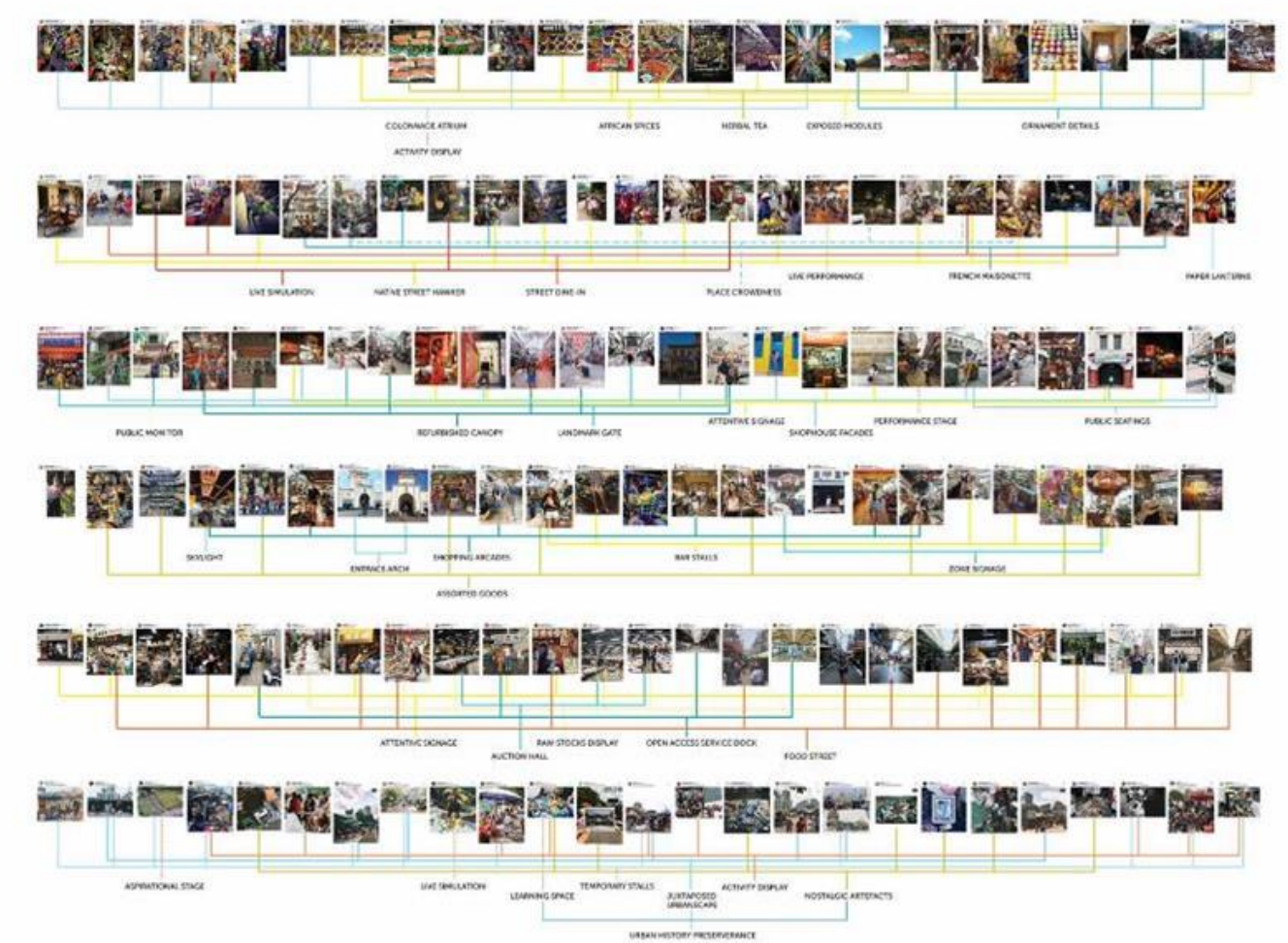

-
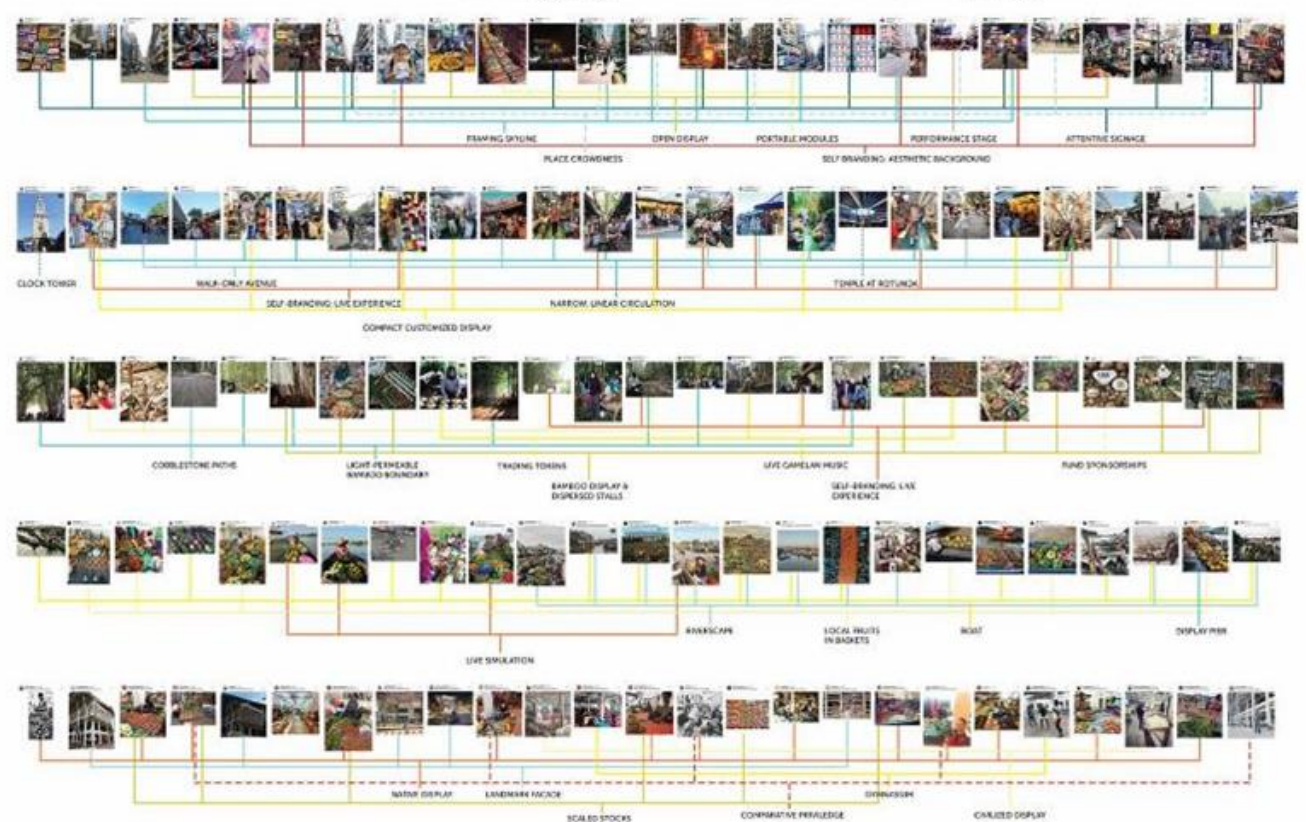

Gambar 2. Kumpulan citra pasar pada laman pencarian Instagram berbasis koordinat lokasi yang berhasil dikumpulkan oleh penulis.

Sumber: Instagram, 2019

\section{DISKUSI DAN HASIL}

Dalam penelitian ini, penulis menemukan beberapa kecenderungan perilaku milenial dan respon ruang terhadap pasar yang berhasil diabadikan dalam photovoice postingan instagram mereka masing-masing. 

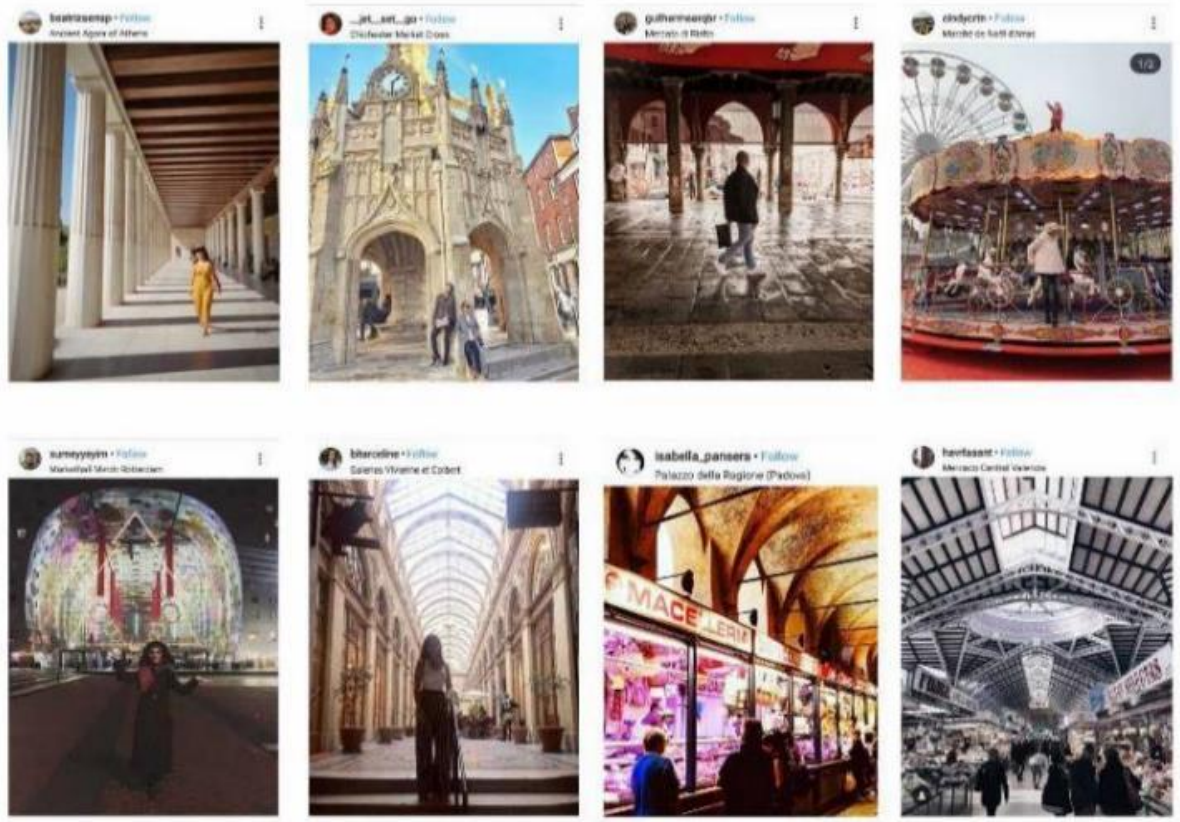

Gambar 3. Foto-foto yang diambil pada beberapa lokasi pasar di Barat Sumber: Instagram, 2019
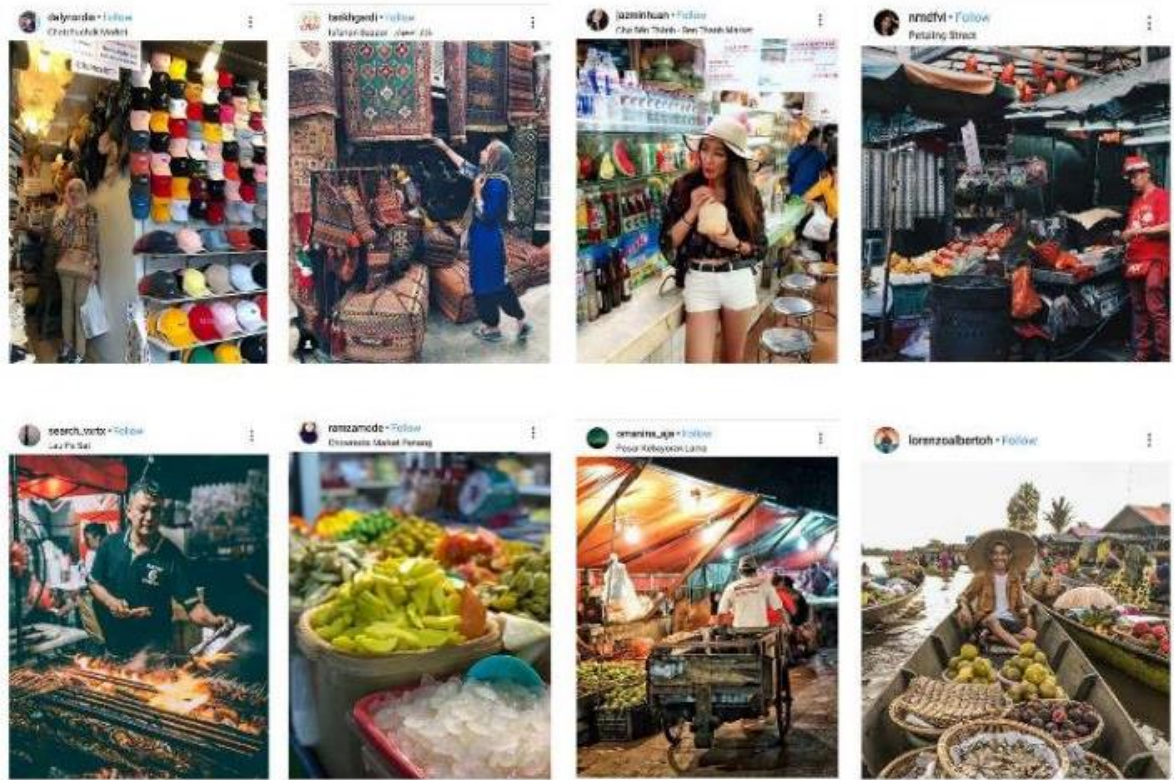

Gambar 4. Foto-foto yang diambil pada beberapa lokasi pasar di Barat Sumber: Instagram, 2019

Foto-foto yang diambil pada pasar-pasar di Barat (Eropa dan Amerika Utara) cenderung menonjolkan komposisi skala dan perspektif arsitektural dari struktur fisik pasar. Detail pertokoan maupun aktivitas perdagangan dalam pasar-pasar tersebut tidak banyak disorot, hanya menjadi elemen pelengkap foto saja. Para subjek foto juga cenderung menempatkan dirinya berada di pusat bidang foto, dan berusaha menonjolkan figur mereka sedominan mungkin lewat permainan skala subjek dengan latar objek bangunan belakangnya. Gestur tubuh para subjek dalam foto juga cenderung pasif, dengan tendensi gestur sekedar berjalan melintas, duduk, bahkan hanya berdiri secara canggung sambil mengamati arsitektur bangunan pasar. 
Sementara tendensi sebaliknya terjadi pada postingan pasar-pasar di Timur (Asia), dimana subjek utama foto sebagian besar merupakan kegiatan perdagangan dalam pasar. Pada sebagian foto yang diambil lebih merekam objek komoditas dagangan spesifik yang hanya ada pada beberapa pasar. Komposisi latar skala dan perspektif pasar tidak begitu diperhatikan (kecuali pada postingan pasar-pasar di Singapura yang berorientasi kuat seperti gaya postingan di Barat). Gestur subjek foto juga cenderung melakukan imitasi terhadap kegiatan pasar yang mereka foto, dengan seolah-olah memeragakan dirinya tengah ikut berdagang atau bertransaksi membeli produk dagangan. Para subjek milenial menempatkan dirinya seara aktif berpartisipasi dalam aktivitas pasar-pasar tersebut.

Dua pola respon subjek foto ini sebenarnya mencerminkan tendensi milenial melihat pasar sebagai media pembangun nilai sosial dalam diri mereka. Dengan membagikan foto-foto dalam pasar, para milenial ini berupaya membangun citra sosial diri mereka yang aktif, baik dengan melakukan kegiatan transaksi langsung maupun sekedar berpose di depan/dalam bangunan pasar sendiri. Pasar secara fisik tereduksi menjadi sekedar properti pelengkap usaha kontruksi citra diri mereka. Walau demikian, secara tidak langsung para milenial ini juga menekankan esensi pasar sebagai simpul interaksi sosial berbagai pelaku di dalamnya. Fakta ini sangat jelas terlihat pada postingan pasar-pasar dari Timur.

Berangkat dari fakta ini, peneliti terdorong untuk mengajukan tipologi pasar baru yang tetap mempertahankan fungsi sosial di dalamnya, dengan menyediakan ruang-ruang komunal dalam pasar. Ruang-ruang komunal ini didistribusikan secara acak dalam beberapa massa bangunan pasar, dan kemudian disebarkan kembali pada lantai-lantai area dagang aktif dalam pasar. Distribusi ini dimaksudkan untuk mendorong pengguna pasar, terutama milenial, untuk bisa mengeksplorasi segala ruang aktivitas pasar dan memungkinkan interaksi lebih intens dengan pelaku-pelaku pasar lainnya. Dan detail rancangan setiap area komunal dalam pasar ini dibuat bervariasi untuk memperkaya keberagaman pengalaman ruang yang dapat diakses penggunanya. Diferensiasi desain ini mengikuti prinsip-prinsip heterotopia milik Michael Foucault.

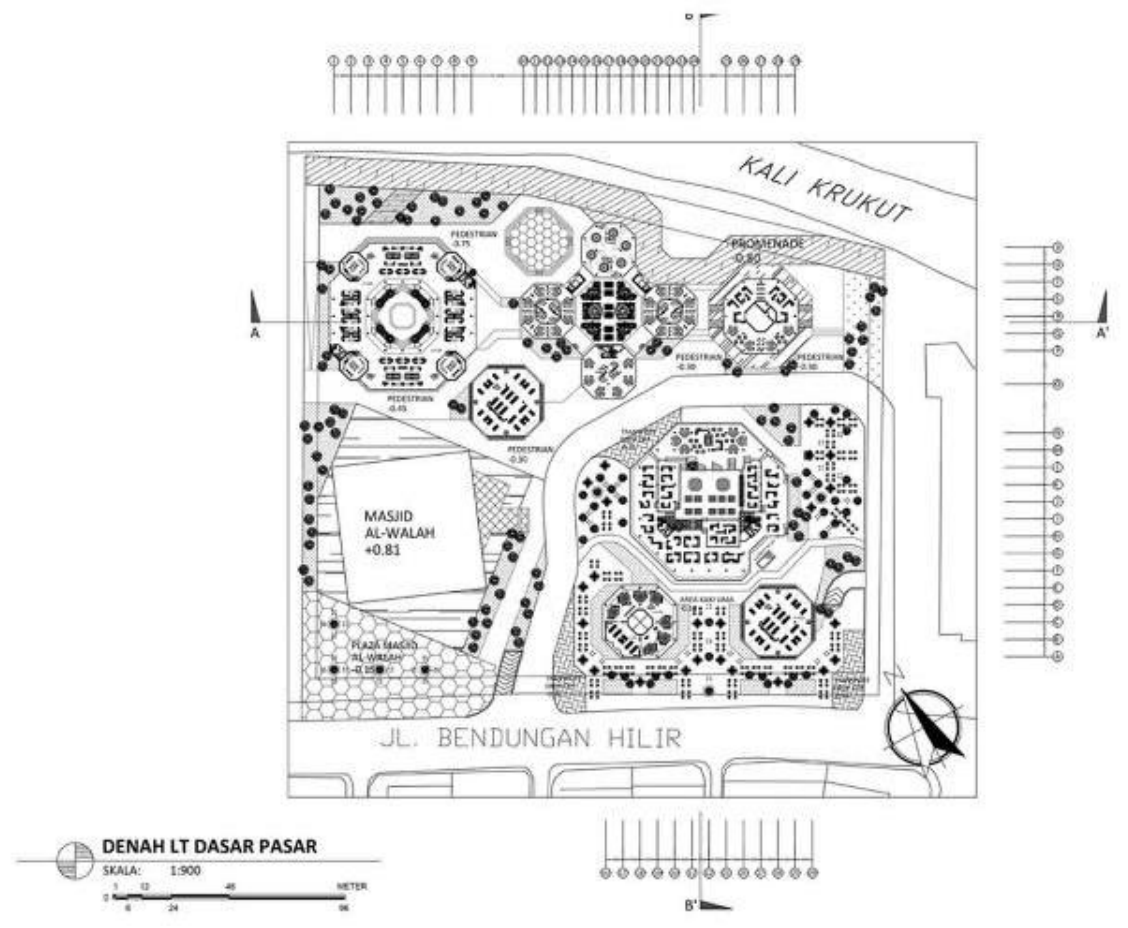

Gambar 5. Rencana Denah Lantai Dasar Pasar Heterotopia Sumber: Penulis, 2019 

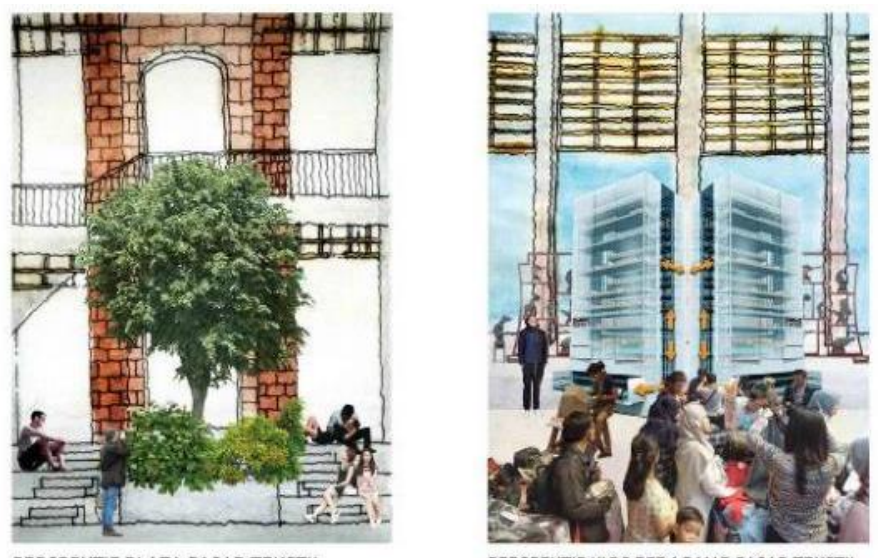

PERSPEKTIF PLAZA PASAR TEKSTIL

PERSPEKTIF KIOS PEDAGANG PASAR TEKSTIL

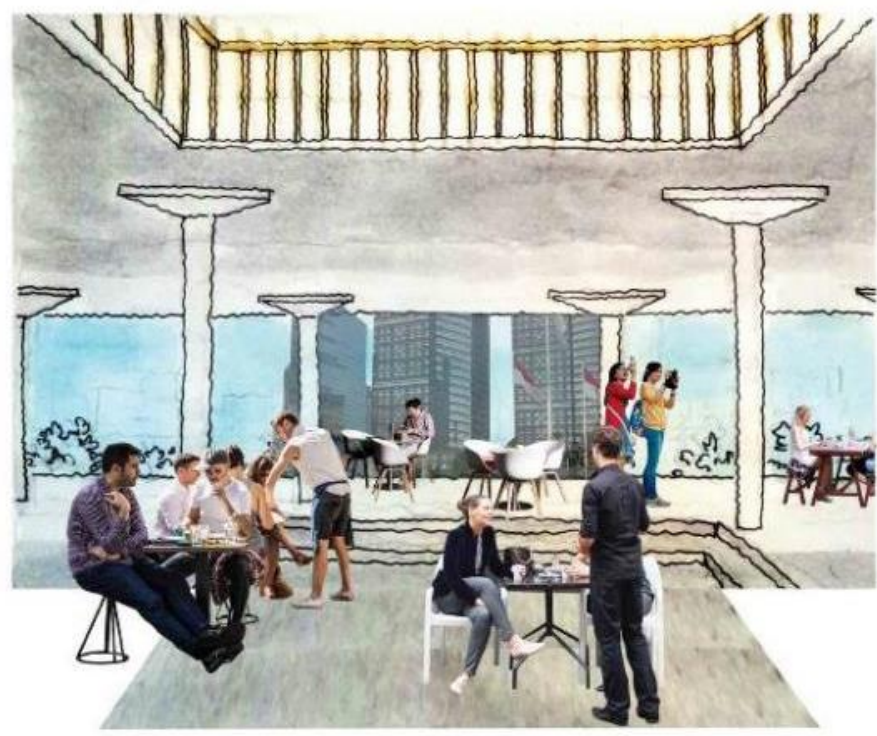

PERSPEKTIF PUJASERA LANTAI DASAR PASAR KERING
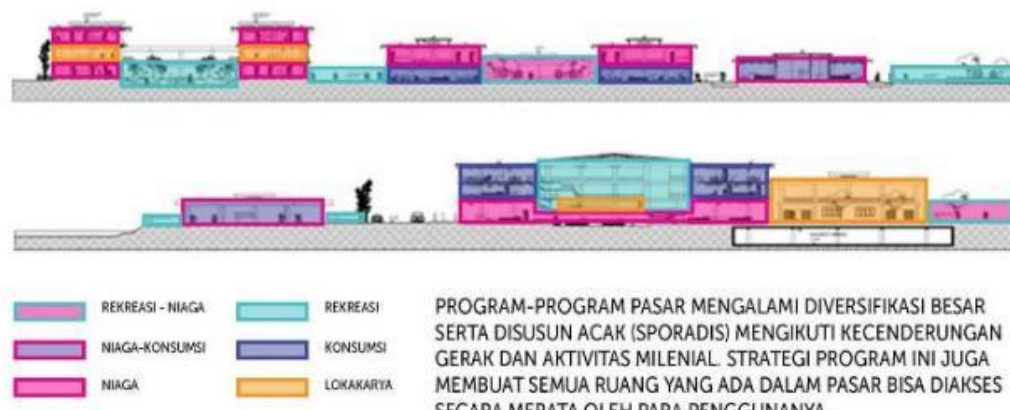

PROGRAM-PROGRAM PASAR MENGALAMI DIVERSIFIKASI BESAR SERTA DISUSUN ACAK (SPORADIS) MENGIKUTI KECENDERUNGAN GERAK DAN AKTIVITAS MILENIAL. STRATEGI PROGRAM INI JUGA MEMBUAT SEMUA RUANG YANG ADA DALAM PASAR BISA DIAKSES

Gambar 6 \& 7. Visualisasi aktivitas-interaksi dalam pasar heterotopia dan distribusi program aktivitas dalam pasar.

Sumber: Penulis, 2019

\section{KESIMPULAN DAN SARAN}

Melalui rangkaian penelitian dan analisa yang telah dilakukan oleh peneliti, dapat ditarik kesimpulan sebagai berikut:

a. Generasi milenial memandang kegiatan transaksi-ekonomi sebagai salah satu cara untuk memperoleh pengalaman baru yang patut dibagikan. Merujuk pada misi partisipatoris perancangan yang dibawa oleh peneliti, para milenial cenderung mengambil peran ganda sebagai konsumen sekaligus pelaku dalam kegiatan pasar di masa ini. 
b. Rancang tipologi arsitektur yang ditawarkan oleh peneliti diharapkan memberi peluang seluas-luasnya bagi para penggunanya, teristimewa generasi milenial, untuk mengekplorasi berbagai peran sosial mereka dalam pasar.

\section{REFERENSI}

Arsitoteles. Politics. Mumbai, India: Wilco.

Mumford, L. (1961). The City in History. London, UK: Penguin Books.

Mumford, L. (1970). The Culture of Cities. Orlando, FL: Harcourt Brace Joranovich. Inc. 